\title{
Chapter 2 \\ Biodiversity, Physical Health and Climate Change: A Synthesis of Recent Evidence
}

\author{
Sarah J. Lindley, Penny A. Cook, Matthew Dennis, and Anna Gilchrist
}

\begin{abstract}
We are at a point in history marked by unprecedented changes in the environmental foundations of human health and well-being. At the same time, the demands from human populations have never been greater, with profound differences in how we engage with the natural environment. By the middle of this century, when climate change impacts are further increasing, the United Nations expects the global population to be approaching 10 billion. In this chapter, we provide a synthesis of published evidence of the complex and important relationships between elements of biodiversity, health and climate change. We draw primarily on reviews conducted in the past five years supplemented with evidence on additional themes. We also develop a detailed case study example focused on urban climate, climate change and biodiversity, taken from the perspective of a large and representative conurbation. The case study uses a body of existing published evidence together with new data and insights to demonstrate important pathways, impacts and outcomes. We end by identifying a set of research questions and stress the need for even more extensive multi-disciplinary and multi-sector approaches. Nevertheless, despite the need for more knowledge, it is already clear that more effective action could, and should, be taken.
\end{abstract}

Keywords Biodiversity $\cdot$ Health $\cdot$ Climate $\cdot$ Review $\cdot$ Mechanisms $\cdot$ Urban

\footnotetext{
S. J. Lindley $(\bowtie) \cdot$ M. Dennis

Department of Geography, School of Environment, Education and Development, University of Manchester, Manchester, UK

e-mail: sarah.lindley@manchester.ac.uk

P. A. Cook

School of Health and Society, The University of Salford, Salford, UK

e-mail: p.a.cook@salford.ac.uk

\section{A. Gilchrist}

Department of Planning and Environmental Management, School of Environment, Education and Development, University of Manchester, Manchester, UK

e-mail: anna.gilchrist@manchester.ac.uk
} 


\section{Highlights}

- Biodiversity, health and climate change have multi-scale and interdependent links.

- Few studies explicitly connect climate change with biodiversity and physical health.

- The full extent of human health impacts from biodiversity losses is unclear.

- Action is needed due to climate projections, biodiversity losses and health demands.

- New research agendas demand ambitious, multi-disciplinary and cross-sector approaches.

\subsection{Introduction}

Few would now dispute that important links exist between the natural environment and human physical health. Nevertheless, despite considerable progress in conceptualising and understanding relationships, there is still much to learn about particular connections, their underlying mechanisms, causality and inter-relationships (Sandifer et al. 2015; Ziter 2016; Cameron and Blanusa 2016).

Biodiversity is considered one of the underlying requirements for beneficial functioning of ecosystems for human health and well-being and is enshrined as such within policy-focused arenas (Lovell et al. 2014; Sandifer et al. 2015). However, the many interpretations of the term biodiversity, the ways in which it is measured and its inter-relationships with other factors, including climate, present considerable challenges for building and testing hypotheses (Schmeller et al. 2018). Where hypotheses relate to impacts on human health, there are still more elements to consider, including an appreciation of direct and indirect pathways, relevant controls and the interdependencies between psychological and physiological processes.

Climate change is known to be modifying the natural environment and how it functions in relation to human health (Bonebrake et al. 2018). For example, climate affects ecological states and processes. As climate changes, it affects the functioning of ecosystems in terms of the quantity and quality of functions with a beneficial role for human physical health. Climate change is also affecting the relative balance of benefits and disbenefits. Furthermore, it has been implicated as one of the mechanisms driving global biodiversity loss, though in fact it is just one of a suite of factors that remove and degrade associated ecosystems. Data from 63 protected areas in Germany collected over 29 years has shown a three-quarters reduction in the biomass of flying insects, a much higher loss than previously supposed (Hallmann et al. 2017). However, analysis of climate variables suggested no strong climate signal to explain the decline. While not all climate-related factors could be discounted, other large-scale factors were also thought to be contributing, in this case agricultural intensification. Similarly, although climate change leads to health impacts, such as through climate extremes like high temperatures and climate-related 
events like flooding, health trends are also influenced by social, political and wider environmental factors.

Climate and biodiversity act as important 'boundary conditions' for human health and well-being. These boundary conditions exert an influence on many of the other elements that affect the health and well-being of individuals through natural environments and associated ecosystem functions (Barton and Grant 2006; Dahlgren and Whitehead 2007). The health status of any one person can be seen as a composite of: individual characteristics (e.g. hereditary genetics), the living environment and life experiences, both physical and social (Fig. 2.1 (left)). Health is determined not only through external ecosystem-related processes and factors, but also internal ones, for example, recognising that the human body itself hosts complex and biodiverse ecosystems that have differing impacts on physical health (Garrett 2015; Ruokolainen et al. 2017) (Fig. 2.1 (right)). External factors include the abundance, type and quality of the natural environment underpinned by 'external' biodiversity. Other external factors include social connections (e.g. family and community), access to health infrastructure and income (e.g. through diet). Inevitably, all are related to some extent to wider socio-economic and political contexts.

The overarching aim of this chapter is to summarise the current evidence of the links between nature, biodiversity, health and climate change, with a particular emphasis on physical health and well-being, defined as "the quality and performance of bodily functioning. This includes having the energy to live well, the capacity to sense the external environment and our experiences of pain and comfort"

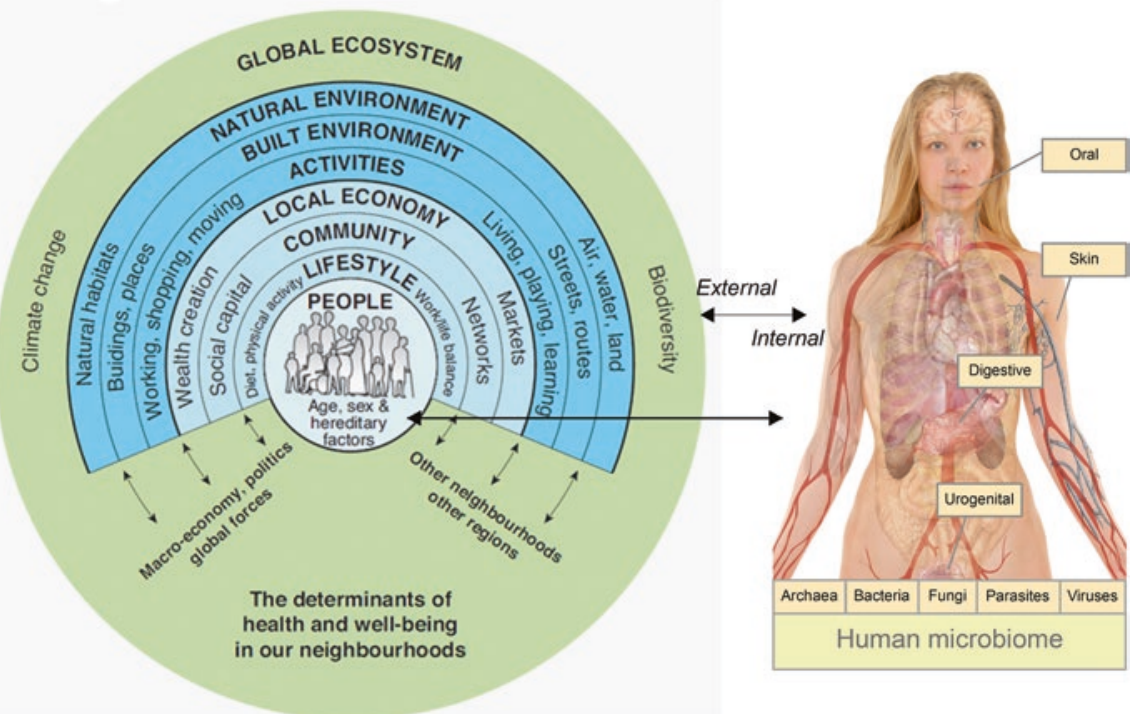

Fig. 2.1 Determinants of human health and well-being (Barton and Grant 2006, based on Dahlgren and Whitehead 1991), including biodiversity at the human scale (after Garrett 2015, Ruokolainen et al. 2017) 
(Linton et al. 2016). In the summary, we primarily draw on existing reviews conducted in the past five years supplemented with review evidence on additional themes such as diet. The chapter also covers three sub-aims. First, we consider the evidence for nature's contributions to physical health from the broad perspective of the natural environment (see Sect. 2.2). We look at direct and indirect ways that natural systems influence human health and well-being with reference to the 11 body systems. Given that the body's systems are highly interconnected, the discussion inevitably connects with material presented in other chapters in this volume (e.g. Cook et al. Chap. 11, this volume). Within the scope of this review and synthesis, it is also inevitable that not all of the evidence can be covered. Nevertheless, the section shows some of the key mechanisms through which human physical health is influenced, according to the most recent literature. Second, we aim to take a closer look at the importance of different forms of 'nature', but with a particular focus on biodiversity (see Sect. 2.3). In cities, nature is often thought of as essential urban green infrastructure - the means through which vital ecological and biodiversityrelated functions (e.g. habitat provision and landscape connectivity) and most nature-derived human benefits are delivered (Benedict and McMahon 2002). However, cities and their populations cannot be considered in isolation. Therefore, the chapter touches on how the protective role of biodiversity operates through diverse pathways, how it functions at different human and geographical scales and when it is most significant during the life course. The protective role includes, but is not limited to, the regulation of disease emergence, micro-nutrient availability for human sustenance and the promotion of contact with symbiotic bacteria necessary for building up tolerances to environmental allergens (Ruokolainen et al. 2017; Rogalski et al. 2017). Thirdly, we provide an overview of some of the important ways that climate change impacts physical health and the natural environment, including through biodiversity (see Sect. 2.4). A particular emphasis is given to how climate change increases potential poor health burdens (including for example in terms of high temperatures and air pollution in urban areas) and also how extreme climate-related events and long-term climatic trends can erode the beneficial physical health effects of nature, green spaces and biodiversity (LWEC 2015; European Environment Agency 2017). Before concluding on emerging research agendas, the chapter ends with a detailed case study example, focused on urban climate, climate change and biodiversity, primarily from the perspective of how the regulating functions of different plant species vary (see Sect. 2.5).

Much of the focus of this chapter is on urban areas. Urban areas are where the majority of the population now resides - nearly three quarters in Europe, with $41 \%$ in the most densely populated centres (European Environment Agency 2018) where stressors on human health and well-being tend to be most extreme. Evidence is drawn primarily from a European context, supplemented with evidence from elsewhere, where possible. It is recognized that this focus gives a particular perspective on connections and the challenges faced that may not be echoed in all contexts. 


\subsection{Nature's Contributions to Physical Health}

In this section, we consider how ecosystems influence human physical health. We discuss direct and indirect pathways which connect the natural environment to human physical health with a particular emphasis on ecosystem regulatory functions (e.g. modification of environmental stressors) and provisioning functions (such as the use of ecosystems by people for food, fresh water and fuel). For example, direct pathways include the health benefits from the consumption of nutritious food and indirect pathways include health benefits due to increased physical activity rates associated with the natural environment. In making this distinction, it is important to note that beyond the more obvious examples given above, the type and form of pathways are not always fully clear. Whether a process is considered direct or indirect may differ depending on the primary consideration in hand, be it human biological systems, physical environmental systems or some specific form of exposure. We consider the evidence from the perspective of the commonly recognised body organ systems, each of which provides a particular function for physical health. The identified body systems are then referenced in subsequent sections of the chapter.

The body has 11 interlinked systems: reproductive, integumentary (skin/hair), skeletal, muscular, nervous (brain/brain activity), circulatory/cardiovascular (blood/ transport of nutrients), endocrine (glands/hormones), lymphatic (associated with immune functions), digestive (food), respiratory (breathing) and urinary/renal (waste). Numerous physiological parameters associated with these systems can be measured to determine physical health. In turn, each parameter can be assessed in order to establish underlying mechanisms for the influence of nature, whether through evidenced processes or through ones that are currently only hypothetical. Psychological parameters have been the focus of much of the existing body of research on exposure to nature and the connection between nature and human health. Associated study outcomes have tended to identify positive links between nature and health (Keniger et al. 2013). However, the range of health benefits is much wider, including in terms of cognitive function, social interaction and improved resilience (Sandifer et al. 2015).

Sandifer et al. (2015) identify no fewer than 27 published examples of the physiological health benefits of interaction with nature (broadly defined as living things and associated landscapes in a wide variety of settings). While some are very broad indicators, others refer to specific physiological metrics, including reduced sympathetic/parasympathetic nerve activity, faster healing after illness, surgery or trauma and positive influences on diabetes. Nevertheless, some reviews point to a more inconsistent picture for specific physiological outcomes. For example, positive outcomes are shown for circulatory/cardiovascular, endocrine and immune systems but with a good deal of mixed evidence (Haluza et al. 2014). Figure 2.2 considers evidence from the perspective of different pathways, but also highlights inconsistencies in the evidence base. 


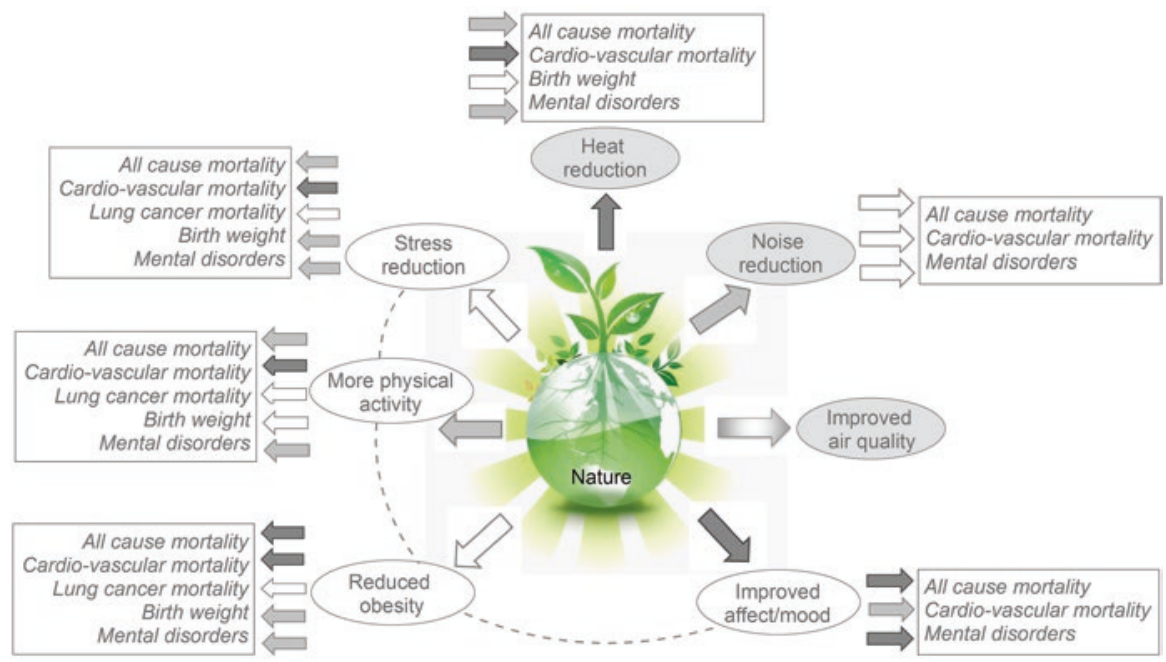

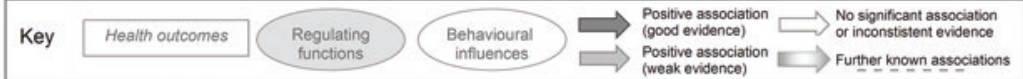

Fig. 2.2 Pathways for physiological outcomes associated with 'exposure to natural environments' (after van den Bosch and Sang 2017)

Interestingly, much of the evidence cited in Haluza et al. (2014) is related to Japan's 'Shinrin-Yoku' (forest-bathing) with most consistency shown for evidence of short-term restorative effects in physiological parameters associated with the cardiovascular, endocrine and immune systems. Studies covered a range of activity types, time periods and populations, but bias is a potential issue due to underreporting of negative or inconclusive findings and a tendency towards short-term studies (Hartig et al. 2014; Haluza et al. 2014). There is less evidence for cumulative effects and therefore how they may translate into measurable mortality and morbidity outcomes (ibid.).

Some of the published evidence relates to effects that are seen as a result of simply being in 'natural' spaces (Haluza et al. 2014). In this context, at least some of the associated mechanisms may be direct, for example physiological responses linked to feelings of well-being inspired by direct engagement with green and blue space (see also Marselle Chap. 7, this volume). Feelings of well-being may come about through impacts on the nervous system and are thus difficult to separate from aspects of psychology and mental health. Nevertheless, the identification of possible direct impacts is important since it suggests that not all of the physical health benefits are associated with physical activity-related physiological responses (given that exercise results in some of the same physiological benefits wherever it is undertaken). That green and blue spaces tend to help to encourage physical exercise is of course also important. More than three quarters of 50 reviewed studies reported 
positive associations between how green an environment is and physical activity rates (Kaczynski and Henderson 2007 in Coutts and Hahn 2015). Similar positive associations are also found between 'blue' spaces and physical activity rates (Grellier et al. 2017; White et al. 2014) (see also Hunter et al. Chap. 17, this volume). Encouragement of physical activity is particularly important in the context of increases in non-communicable diseases (NCDs) related to inactivity, such as Type 2 diabetes (Cook et al. Chap. 11, this volume).

The other important, and increasingly well recognised, pathway explaining why physiological responses might be seen at rest in 'natural' spaces is due to the regulating functions of green and blue spaces through moderating noise, air quality and temperatures. In other words, some health benefits are due to the influence that green and blue spaces have on removing or reducing environmental stressors, especially in busy, densely populated urban centres (Hartig et al. 2014; Coutts and Hahn 2015; Markevych et al. 2017). Indeed, this also makes physical activity undertaken in urban green spaces potentially more healthy since it could otherwise lead to increased exposure to harmful levels of air pollutants with acute or chronic effects on the respiratory and cardiovascular systems (Mölter and Lindley 2015). However, the 'absence of stressors' argument does not explain all associations, such as have been found in studies where physiological responses are seen in response to visual cues with no direct contact, something that points to psychological and sociocultural factors (Clark et al. 2014). Due to the interwoven biophysical, psychological and socio-cultural elements underpinning connections between nature and health some conceptualisations are based on grouped biopsychosocial pathways, specifically pathways that positively influence health through reducing the potential for harm (reducing environmental stresses), restoring capacities (improving recovery functions) and building capacities (reducing individual susceptibility to harm) (Hartig et al. 2014; Markevych et al. 2017) (see also Marselle et al. Chap. 9, this volume).

The role of reduced exposure to environmental noise is one particularly interesting example given that reductions in noise exposure have been given relatively little emphasis in earlier models, e.g. Hartig et al. (2014), compared to those developed more recently, e.g. Markevych et al. (2017) and van den Bosch and Sang (2017). Explanatory mechanisms have also been proposed to link noise stress with impacts on cardiovascular, respiratory, immune response and metabolic health through stress-response models (Recio et al. 2016). Similar processes may apply to some of the other common environmental stressors, in addition to the better known, but still imperfectly understood connections. For example, new research is finding a wider range of connections between air pollution and human health than ever before, not just through morbidity and mortality from cardiovascular and respiratory diseases but also through neurodevelopmental disorders and birth defects (Landrigan et al. 2018). It should be remembered that environmental stresses also affect other animals and have been linked to biodiversity loss. Although an issue that is particularly acute in urban areas, anthropogenic sources have been found to elevate noise levels 
in more than a fifth of protected areas in the USA, reaching levels known to have negative effects on wildlife (Buxton et al. 2017).

Direct physical health outcomes from ecosystem functions may be difficult to evidence for some pathways, but one more obvious direct way that nature influences physical health is through human sustenance and micro-nutrient availability. Primary production from plant materials is the initial source of food energy for all living beings, and humans directly consume $25-50 \%$ of the energy embodied in plant-life even before considering the consumption of animals that plants also sustain (Coutts and Hahn 2015). However, human health is not just a matter of the quantity of energy consumed but also its diversity. Diversity in diet and the micronutrient supply this provides is something that can be linked to wider ecological biodiversity too (see Sect. 2.3).

Plants and other natural sources are also responsible for a large proportion of the medicines currently in use today, contributing to almost a third of all marketed drug products sold (Coutts and Hahn 2015). Bioactive compounds, and their role in disease prevention and ageing, are still the subject of much important research. For example, evidence for the anti-microbial properties of phenolics in berries is important in the context of growing antibiotic resistance (Paredes-Lopez et al. 2010). Polyphenols from berries also have a range of other positive functional properties, including anti-inflammatory, neuro-protective, anti-oxidant, anti-cancer and antimutagenic roles (Nile and Park 2014). Polyphenols are just one of the bioactive compound groups found in berries, which are also rich sources of vitamins and minerals (ibid.). Brassica vegetables are associated with anti-cancer properties as well as a range of other health benefits (Moreno et al. 2006). Other food groups have similar beneficial properties, such as seaweed and fungi.

These provisioning functions of ecosystems (such as the use of ecosystems by people for food, fresh water, fuel and animal forage) are a critical component of human health with a huge literature and evidence base. Fuel from ecosystem sources (e.g. wood) impacts health too, including cooking, facilitating water purification and also via the improved ability for people to moderate living conditions. The connections between provisioning functions and health can be indirect, for example through the role of pollinators in agricultural systems (IPBES 2016). Relationships can be complex with both beneficial and detrimental roles for human health, varying between and within species and also in response to local environmental factors. For example, a recent study of crops across five continents found that some $39 \%$ of crop flower visits are from insects other than bee species (such as flies and wasps) and the relative importance varies considerably by crop type and location (Rader et al. 2016). In other contexts, some of these species are regarded as pests and can be associated with negative health effects, such as via food contamination. 


\subsection{Biodiversity and Physical Health}

In this section, we consider the range of connections and pathways between biodiversity and human physical health, beginning with the scale of the human body before looking at processes operating at wider spatial scales. Given that much of the evidence in the previous section considered the natural environment in a broad sense, here we examine how biodiversity metrics are linked to ecosystem functions affecting physical health.

In considering the role of biodiversity on human health it is useful to start by recognising the human body as an ecosystem, with both internal and external microbiota, something that has been termed the human core microbiome (Karkman et al. 2017). The human gut alone contains some 1,014 bacterial strains and species as well as other micro-organisms and viruses, the mix of which is unique to each individual and which changes during the life course (Odamaki et al. 2016; Seksik and Landman 2015). The concept of the exposome has been developed to recognize the role of factors shown in Fig. 2.1 in determining human health and well-being, the significance of environment and how human health is affected by cumulative influences over time, and therefore the life course (Renz et al. 2017). Renz et al. (2017) further propose the meta-exposome as a means of connecting human exposures with those of the wider biosphere and linking ecosystem health at all scales to human health (Fig. 2.3), a notion that is echoed elsewhere (e.g. Sandifer et al. 2015).

Major microbiota colonisation events are associated with particular parts of the human life cycle, such as birth, but continue throughout the life course dependent on lifestyle, environment and exposure (Ruokolainen et al. 2017). The so-called 'old friends' hypothesis also relates to this process of gaining health benefits from beneficial symbiotic microbes. Benefits are associated with many of the body organ systems and are multi-functional. For example, as well as helping with the healthy development of the immune system, beneficial microbes can also perform protective roles when human hosts encounter allergens (Rook 2013; Ruokolainen et al. 2017). Both environmental and behavioural factors are involved in the development of dysbiosis, where alterations in microbiota may result in a negative cycle of illheath (Fig. 2.3). Dysbiosis is also implicated in problems associated with the integumentary, digestive and urinary/renal systems as well as disorders in the respiratory and cardiovascular systems (Carding et al. 2015; Renz et al. 2017). Lack of contact with sources of symbiotic microbiota is one of the outcomes of people's growing 'extinction of experience' of natural environments, and lack of contact even of itself tends to promote greater disassociation (Cox and Gaston 2018).

Of course, biodiversity does not just affect human health through the body's own ecosystem. As well as affecting humans directly, such microbiota relationships also underpin the healthy functioning of wider ecosystems on which humans depend (Flandroy et al. 2018). Biodiversity is also important at community, neighbourhood and regional scales. For example, in Australia, where $31 \%$ of the population are estimated to be affected by long-term respiratory conditions, after socio-economic factors, the second and third most important determinants of 


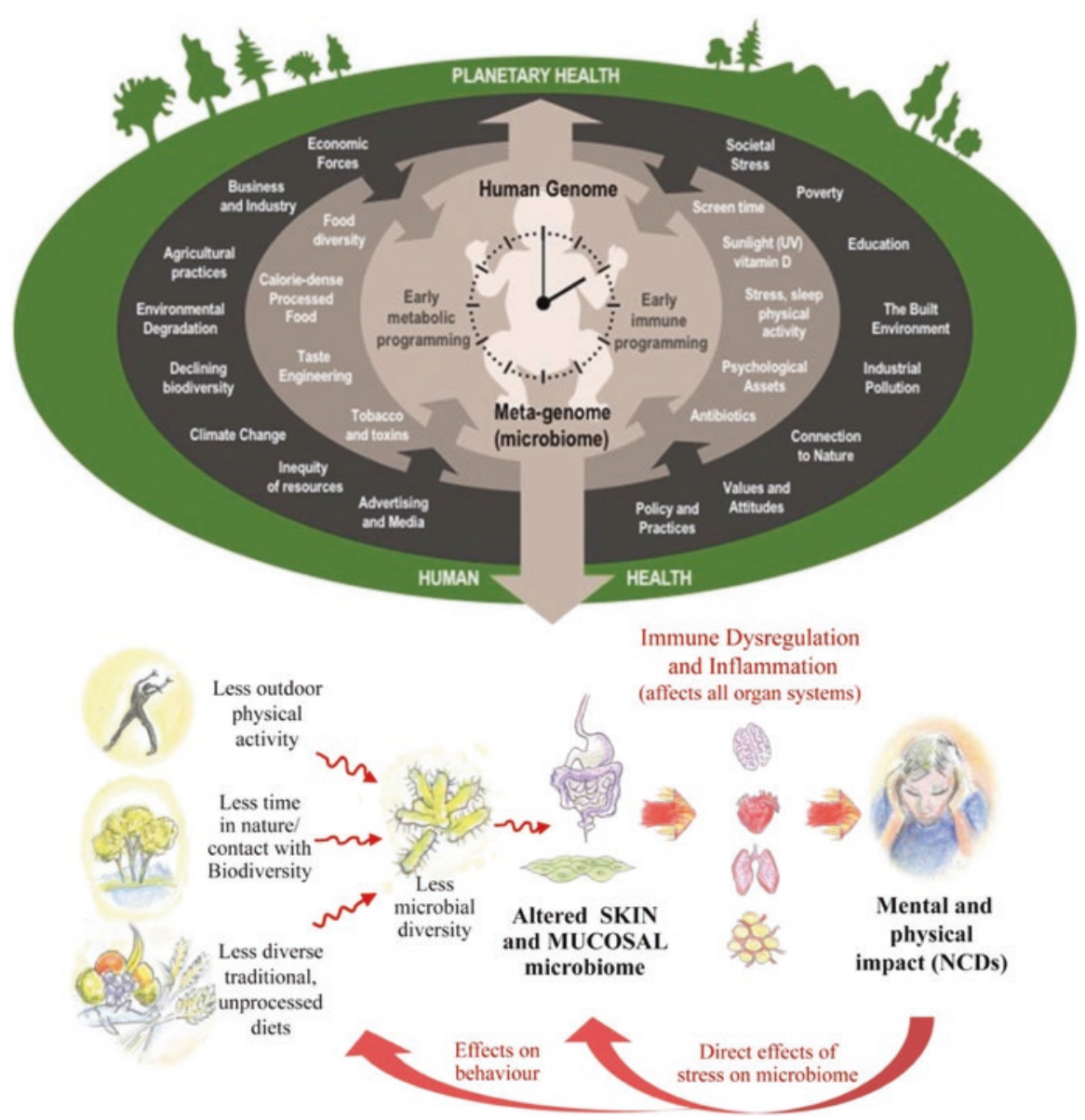

Fig. 2.3 The inter-relationships between human and ecological health as expressed through the exposome concept (top) and the pathways to reductions in physical health through dysbiosis (bottom) (Renz et al. 2017)

positive respiratory health are associated with landscape biodiversity (vegetation diversity and species richness) (Liddicoat et al. 2018). Many critical ecosystem processes operate on much larger spatial scales and ultimately impact global processes through the effect that ecosystems exert on wider natural systems, such as climate, water and air quality, and the impact that they have on food nutritional quality and diversity (Harrison et al. 2014; Ziter 2016; Schwarz et al. 2017). Nutritional diversity is important for ensuring good physical health (Lovell et al. 2014), but biodiversity in agricultural systems is important for a range of other reasons, such as supporting ecosystem health (and therefore functions such as pollination and soil regulation) and protecting against potential problems from pests 
and diseases in large areas of monoculture crops (Dobson et al. 2006). In turn, biodiversity ultimately affects human health by making agricultural systems more inherently resilient and less liable to large scale losses (Dobson et al. 2006). Evidence also suggests a link between biodiversity and the productivity of systems for human use, for example more biodiverse woodlands and fisheries are more productive for fuel and food (Harrison et al. 2014).

In order to understand mechanisms in more detail, it is necessary to unpack the concept of biodiversity and understand how, where and when its different elements are important. Otherwise, there is considerable potential for uncertainty and the potential to equate 'ecosystem services' and 'biodiversity' so that they are seen as essentially the same thing (Mace et al. 2012). Indeed, there is still considerable disagreement about which ecosystem and biodiversity metrics should be considered (ibid.), with most reviews considering metrics beyond those implied by the definition used to frame this volume. Figure 2.4 shows two examples of diagrammatic representations of biodiversity metrics and the functions of ecosystems known to influence human health, a number of which relate to the pathways that have already been identified in Sect. 2.2.

Figure 2.4 (top) identifies a range of biodiversity metrics of different levels of complexity and summarises the available evidence on how they relate to ecosystem functions that have a useful role for people in urban areas. Some of the connections are identified as being positive (red - beneficial for functions) while others are negative (blue - detrimental for functions). For example, Schwarz et al. (2017) (Fig. 2.4 (top)) reviewed 82 studies that examined taxonomic diversity and its links to useful ecosystem functions in urban areas. The studies identified positive connections through pollination, soil protection and fertility, pest control, fresh water and environmental regulation. However, the studies also identified some negative connections, even for these same pathways. Therefore, even taking the one example of urban ecosystems, the extent to which there are positive compared to negative effects depends on context and perspective (Díaz et al. 2018). Some of the biodiversity metrics, such as functional identity (associated with 22 studies) were found to have only positive effects on urban ecosystem functions. While it may be assumed that these effects are then positive for human health, this claim cannot be made on the basis of the review findings alone. Figure 2.4 (bottom) identifies ecological elements acting as 'Ecosystem Service Providers', i.e. the conduits through which the various biotic attributes listed act to benefit or harm human beings. For example, a wide range of function providers exist for pest regulation, from single species to functional groups and whole habitats. In this case, most studies have connected pest regulation to species within single functional groups. There are fewer studies considering multiple functional groups which makes cross-connections more difficult to determine. Ultimately considering the impacts of environmental stressors, including climate change, will require the systematic investigation of cross connections and whole ecosystem responses. 


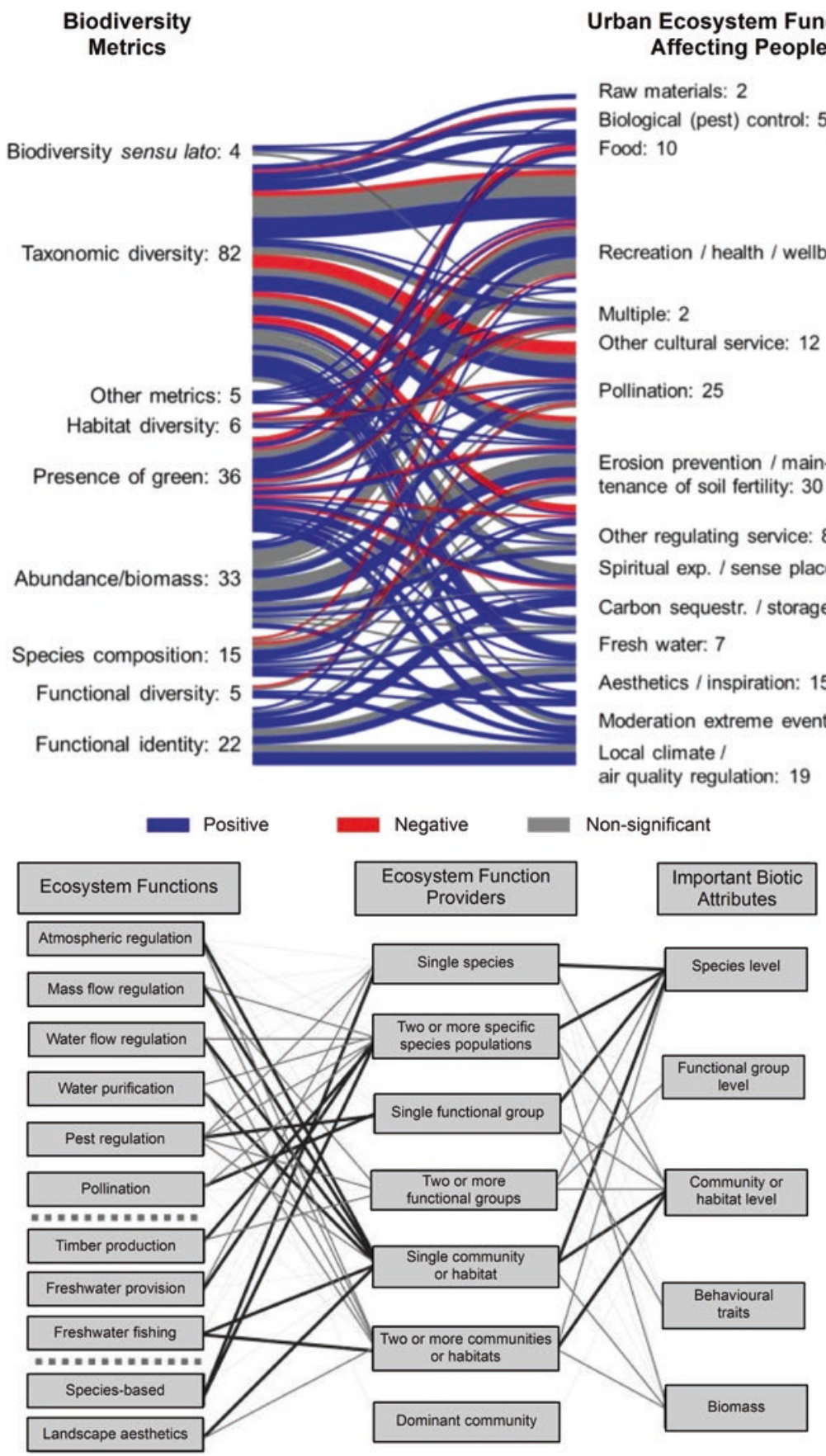

Fig. 2.4 Biodiversity metrics and some of the ecosystem functions underpinning physical human health (top - Schwarz et al. 2017; bottom - Harrison et al. 2014). Linear connections denote the metrics that have been explored, line-width shows the relative proportion of studies and linecolours (top only) indicate the type of associations found 


\subsection{Climate Change and Physical Health}

Climate is an inherent part of the natural systems that are associated with both biodiversity and physical health. Therefore, climate change is similarly interconnected with the processes discussed in the previous two sections, particularly in the context of rapid changes that go beyond the pace of autonomous adaptive capacity and in the context of other drivers of change, such as urbanisation (Fisher et al. 2017). Climate change has direct and indirect influences on the underlying mechanisms of processes discussed in the previous sections. Direct impacts on human health include, for example, the influence of higher temperatures on heat stress in urban dwellers. Indirect impacts include how climate change affects evaporative cooling in urban areas through which people's exposure to high temperature events may be reduced. In this section, we consider the ways in which climate change affects physical health and the role of the natural environment, both generally and through biodiversity. Since biodiversity is also affected by climate change, the section ends with an assessment of climate impacts on the biosphere, particularly in terms of the functions and processes identified in the previous sections as being important for human health.

There are numerous reviews of the deleterious effects of accelerated anthropogenic climate change on natural systems and on human health, as well as those that point to some of the possible benefits. Reviews include the following direct/indirect and primary/secondary pathways (LWEC 2015; European Environment Agency 2017; Fig. 2.5).

\section{- Health effects of heat and heat waves}

Heat-waves are estimated to have resulted in cumulative death rates of 129.0 people per million in Europe between 1991 and 2015, 24 times higher than the next highest most severe extreme weather-related hazards in terms of death rates (which are cold- and flood-related events at 5.3 and 6.4 people per million respectively; European Environment Agency 2017). Heat-waves are well known to be associated with excess deaths particularly in older people, people with pre-existing health problems and people living in urban areas, for example based on analyses of the 2003 European heat-wave (Johnson et al. 2004; Grize et al. 2005; Poumadere et al. 2005). Excess death rates have also been recorded in cities across the world, e.g. in Chicago, Melbourne and Moscow, including cities with populations already adapted to relatively high temperatures (Norton et al. 2015; Burkart et al. 2014). Evidence from the UK suggests that cardiovascular causes result in the larger number of deaths, though tending to be more associated with atrial fibrillation or pulmonary heart disease compared to other heart diseases. Furthermore, excessive heat seems to be most strongly associated with causes of deaths related to the endocrine, nervous and urinary/renal systems (Arbuthnott and Hajat 2017). People with dementia and on some prescribed medications may also be susceptible to heat-related hospitalisation and mortality, possibly due to higher potential for dehydration and/ or reduced ability to sweat (Stollberger et al. 2009). The frequency and severity 


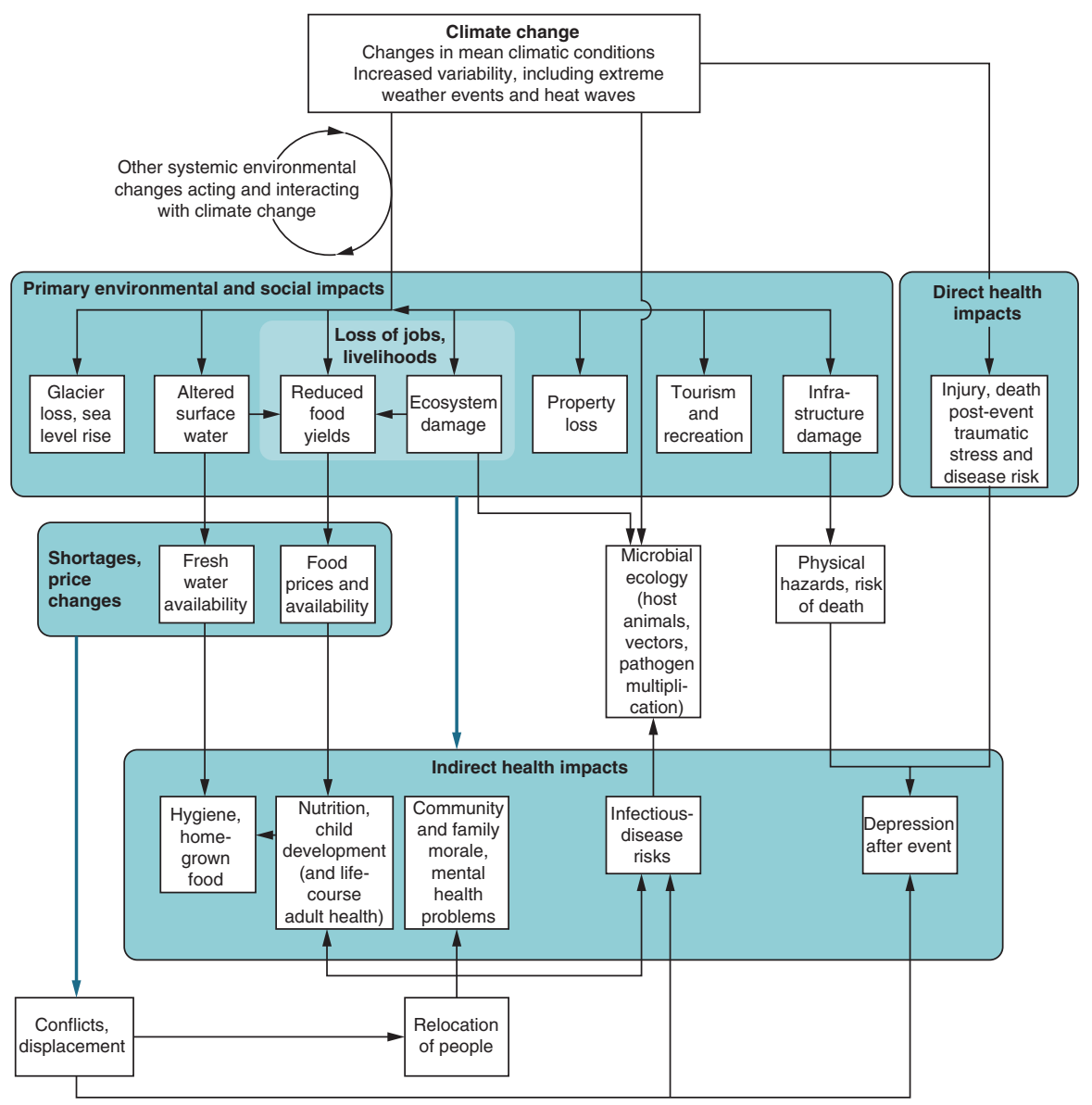

Fig. 2.5 Pathways through which climate change can influence human health and well-being, including though ecosystem-related effects. (McMichael 2013 in European Environment Agency 2017)

(duration and intensity) of events are expected to increase in the future and to be compounded further by other influencing trends, such as an ageing population with higher sensitivity to impacts, the potential for maladaptation in some health and social care systems and the potential for combined impacts from other climaterelated hazards, such as drought, fire and poor air quality (European Environment Agency 2017; Curtis et al. 2017). However, there are also moderating factors, for example, analyses over recent decades in the south of England found no evidence of a substantial worsening of heat-related mortality trends, something that analysts have attributed to successes in national scale adaptation actions and improvements in health and health systems more generally (Arbuthnott and Hajat 2017). 


\section{- Health effects of milder winters}

Cold weather events are well known to be associated with excess mortality and morbidity (European Environment Agency 2017). For example, all of the UK's devolved nations report increases in all-cause mortality with reducing temperatures below health-related baselines, though mortality tends to be due to secondary impacts on the cardiovascular and respiratory systems rather than due to hyperthermia (Hajat 2017). As with high temperature events, factors other than temperature are also important, including building insulation, the availability, efficiency and cost of heating and social factors, such as awareness, all of which vary spatially (Robinson et al. 2018). By extension, milder winters do not necessarily result in a reduction in cold weather impacts. Nevertheless, all other things being equal milder winters should have health benefits in view of warmer mean temperatures (fewer Heating Degree Days) and fewer extreme cold-weather events (European Environment Agency 2017). Incidence rates and timings of influenza and other infectious diseases are linked to climatic drivers, therefore there are likely to be secondary effects. Although changes have been observed in influenza peaks and seasons, climatic and other determinants are currently uncertain (Caini et al. 2018).

\section{- Outdoor air quality}

Like other impact groups, air quality is also greatly influenced by factors other than climate change, with changes in emissions being particularly important over short time horizons. For example, regional haze in South East Asia is ultimately caused by biomass burning, though exacerbated by other climate-related factors. Even far from initial sources, haze has been linked with multiple impacts on physical health, including through the respiratory and cardiovascular systems due to the predominance of fine particulate matter $(<2.5 \mu \mathrm{m})$ as well as impacts on agriculture and tourism (Latif et al. 2018). Despite the influence of other factors, studies suggest that over the longer term there are likely to be climate penalties associated with a number of air pollutants known to impact both human and ecosystem health e.g. ozone and particulate matter (though with considerable uncertainty). Dust storms are more directly associated with climatic factors and changes in wind and precipitation are likely to affect the distribution and extent of associated health burdens, including respiratory, cardiovascular and infectious diseases (Schweitzer et al. 2018). Alongside more gradual changes to baseline air quality affecting annual average concentrations and chronic human health effects, climate change therefore also has a role in determining the frequency and severity of meteorological conditions that give rise to episodes of poor air quality. Air quality episodes with elevated concentrations of air pollutants can lead to a range of chronic and acute diseases, evidenced by health outcomes that include increased hospital admissions and excess morbidity and mortality rates. The stagnation events associated with air quality episodes can also be associated with summer heat waves and therefore have cumulative outcomes for human health (Doherty et al. 2017). 


\section{- Flooding and health}

Flood events are frequently associated with storms and landslips, which themselves have high numbers of people directly affected, but there are also long-term and indirect impacts from events, such as increased exposure to disease (European Environment Agency 2017). There are numerous pathways through which health impacts are felt and they operate both during flood events and after them, frequently affecting people who have heightened sensitivity due to age or existing health status. Drowning, electrocution and other physical injury may lead to mortality during these events, as well as morbidity associated with injuries, illness from water-borne disease, carbon monoxide poisoning due to the use of generators and cardiovascular effects due the stress of being affected (Lowe et al. 2013). Many of these morbidity factors are also associated with the period following flood events, which is sometimes long and exacerbated by displacement. Lack of power and water supply disproportionately affects people with pre-existing illness and poor mobility and inhibits access to health and social care services, something that can be particularly important when essential medicines have been lost or contaminated (Fernandez et al. 2002; Klinger et al. 2014).

\section{- Emerging infections}

Infectious disease is inevitably influenced by human factors and mobility. However, redistributions of species through climatic change and climatic triggers are also recognised as having a key role in major events in history, such as the bubonic plague in Europe (Bonebrake et al. 2018). Novel species assemblages are expected to be associated with new emergences in the future. See Müller et al. (Chap. 4, this volume) for more on vector-borne diseases and climate change.

\section{- Impacts of extreme events on health services and social care}

In addition to differences in levels of demand for services, the services themselves can be impacted, indirectly affecting physical health. Social, institutional and physical infrastructure systems are interconnected and impacts on one will affect how others are able to operate during heat waves, cold weather events and other climate-related hazards, for example affecting mobility/transport, storage/distribution of medicines, the operation, reliability and efficiency of energy systems, availability of fresh water and access to record systems (Curtis et al. 2017).

\section{- Food-and water-borne disease and contamination}

There are known linkages between climate and the prevalence of food and water borne diseases. They include: campylobacter (seasonal, related to rainfall amounts/ timing and higher temperatures), salmonella (warmer temperatures and flooding, due to potential for contamination), listeria (humidity), vibrio (summer, brackish water), cryptosporidium (drinking/recreational water affected by heavy rain/flooding) and norovirus (winter, flooding/high rainfall) (European Environment Agency 2017). However, the likelihood of higher incidence rates depends on many other factors. For example, strong positive associations between elevated temperatures 
and cases of food poisoning from salmonella could lead to increases in future cases, but future estimates need to be considered in the light of successes in interventions that have led to a low incidence rate in recent years. While the picture for salmonella is one of relative control and decline, this is not true for all intestinal infectious diseases and sometimes knowledge of climatic responses is insufficient to make full assessments (Lake 2017).

\section{- Pollens and other allergens}

Changing human behaviour is also a factor in terms of the extent to which exposures are changed due to a changing climate, something that is likely to affect a range of other stressors. These issues are discussed in more detail in Damialis et al. (Chap. 3, this volume).

\section{- Drought and water scarcity}

The availability of, and access to, water resources is a basic human need and one that is inextricably linked with physical health. Climate change is known to be modifying the cryosphere and affecting fresh water resources (European Environment Agency 2017). Although not the only determinant of water scarcity - where much is driven by socio-political factors and other issues such as water quality and distribution - no account of climate change and physical health would be complete without recognising the essential associations between water and other aspects of health.

\section{- Wildfires and health}

Climate change influences the likelihood and severity of wildfires as a result of extending the 'fire season', the higher susceptibility of vegetation to burn when coming in contact with ignition sources (e.g. due to being water stressed) and the greater likelihood of spread due to the potential for increased growth rates (European Environment Agency 2017; Carporn and Emmett 2009). In the United States it has been estimated that annual respiratory hospital admissions ranged from 5200 to 8500 and cardiovascular hospital admissions from 1500 to 2500 between 2008 and 2012 due to $\mathrm{PM}_{2.5}$ associated with wildland fires (Fann et al. 2018).

Although not an exhaustive list, a considerable number of the themes above are clearly related to ecosystems. Climate change is recognised as one of the main pressures on ecosystems, alongside habitat change and fragmentation, invasive species, land management changes and pollution (European Environment Agency 2017). Climate induced changes have been observed in all land (e.g. changes in species ranges and phenological responses), freshwater (e.g. changes in flow, also related to changes in human extraction rates which are partly climate-related) and marine ecosystems (e.g. changes in species ranges, acidification and sea level rise) (ibid.). Agricultural systems can see both benefits and stresses, the former in terms of increased opportunities through extension of the growing season and the potential for enhanced photosynthesis, but also tempered with the potential for climate extremes, irrigation demand and availability, increased incidence and new emergence of pests and diseases, and unintended consequences resulting from changes to farming practices (European Environment Agency 2017; Bonebrake et al. 2018). 
The balance between positive and negative influences is likely to vary geographically and over time and issues of the transmission of risk must also be considered (Challinor et al. 2018).

Human factors are a key component of the systems through which health effects occur. For example, climate affects transportation networks with higher temperatures making the distribution of perishable goods more challenging and higher rainfall potentially increasing the probability of contamination. Given the increasing concentration of people in urban areas, remote from areas of production, these challenges become more acute. Climate can also affect the nutritional value of some produce. Picking up the example of berries from Sect. 2.2, it is known that climate factors have an influence on the concentrations of phenolics. Phenolic concentrations can also be affected by storage conditions and ripeness as well as species, variety, location and associated environmental interactions (Teixeira et al. 2013; Kellogg et al. 2010; Paredes-Lopez et al. 2010). Thus, the potential for changes in nutritional values of crops as well as their yields under climate change is also a consideration. Diseases and changing distributions of pests and weeds may also affect livestock and fisheries both directly and indirectly (e.g. through the availability of foodstocks) with secondary impacts on human health (European Environment Agency 2017). We have much still to learn of the impact of climate change on ecosystems and biodiversity, including how the interconnections are being felt through mechanisms like the human biome.

\subsection{Exploring a Subset of Interactions Through an Urban Case Study}

The previous sections have shown the complexities of interconnections between biodiversity, climate change and physical health. To explore the complexities further we present a case study which synthesizes evidence from some of the identified links for Manchester, UK. The conurbation of Greater Manchester in the north of England has a population of around 2.6 million people and covers an area of around $1,280 \mathrm{~km}^{2}$. Despite being one of England's largest city-regions, Greater Manchester has been used as a representative urban case in previous studies (Lindley et al. 2006). The case for Greater Manchester being representative has been made due to its varied population and urban character. It is also exposed to a range of different hazards and although some parts of the city are affected by flooding - some of them severely - there is no single hazard which dominates the conurbation as a whole in terms of population risk, physical health or associated decision-making. Accordingly, the representativeness and body of existing research for Greater Manchester make it a good basis for a more focused examination compared with cities that are more distinctive in environmental or political terms. The case study starts from the perspective of high temperatures and heat-waves and through that considers wider impacts and links with other environmental characteristics and processes, including 
some of the biodiversity metrics underpinning how ecosystems influence health outcomes examined in the previous sections.

The Urban Heat Island (UHI) effect is the well-recognised phenomenon whereby cities and towns are often much warmer than surrounding rural areas, particularly at night after calm, sunny days (Oke 1982). The effect can exacerbate the potential for human exposures during periods of high temperature (Wilby 2003). The UHI effect is primarily generated as a result of the physical properties of urban materials, their structure and - to a lesser extent - their use, e.g. through anthropogenic heat emissions (Smith et al. 2009). Built materials have different radiative and thermal storage properties compared to natural surfaces, with the former tending to absorb direct and diffuse short-wave radiation during the day and later re-radiate stored energy back to the atmosphere as long-wave radiation. Where there is higher sky-view factor (the amount of sky which is visible from a point on the ground) stored energy can be re-radiated quickly. However, geometries in cities are complex and low sky-view factor tends to inhibit the loss of long-wave radiation leading to a heating of overlying air during periods of low wind speeds and/or due to inhibited wind flows (Lindberg 2007). In urban areas there is also a relative lack of vegetation and water, which provide cooling functions through evapotranspiration and surface shading in the case of large vegetation stands (Sproken-Smith and Oke 1999). Due to their cooling properties, large areas of vegetation and water within cities play an important role in offsetting urban temperatures, with even modest amounts having an effect (Bowler et al. 2010).

An analysis of temperature records for Manchester has shown that UHI intensities have been increasing over time (Levermore et al. 2017). If trends continue to the end of the century, increases will be similar to those expected with climate change (medium emissions scenario). Increased UHI intensities are likely to be associated with more severe heat-wave events in the future. In the north west of England, a heatwave is defined as a period of time where the maximum temperature exceeds $30^{\circ} \mathrm{C}$ for 2 days with a minimum temperature of $\geq 15{ }^{\circ} \mathrm{C}$ in the intervening night. Using this definition, the number of heat waves is not expected to increase dramatically by the 2050s (according to the central estimate of the UKCIP09 projections (high emissions scenario)) (Cavan 2010). However, estimates based on climate projections do not explicitly consider the additional UHI effect on temperatures (Jenkins et al. 2009). Even without the UHI effect being considered, the number of days exceeding $30{ }^{\circ} \mathrm{C}$ is expected to be around three per annum by the 2050s (Cavan 2010). Monitoring of the UHI carried out between May and August 2010 demonstrated that the UHI effect can add up to $6{ }^{\circ} \mathrm{C}$ (day) and $8{ }^{\circ} \mathrm{C}$ (night) in some locations in Greater Manchester (Cheung 2011). The conurbation could also see up to a $3.4{ }^{\circ} \mathrm{C}\left(2.4{ }^{\circ} \mathrm{C}\right)$ increase in the temperature of the warmest summer day (night), according to the central estimate of the UKCIP09 projections (high emissions scenario) with these highest increases expected for the upland Pennine fringe (Cavan 2010).

Archival studies show that high temperatures in Manchester, even those that could be considered relatively modest elsewhere, are associated with increased hospital admissions rates and excess mortality. In July 2006, an estimated 140 excess deaths in the region were associated with elevated temperatures which reached a 
peak of $31.3{ }^{\circ} \mathrm{C}$ measured at the airport on the southern periphery of the Greater Manchester urban area (Smith and Lawson 2012). Some of the excess deaths from past high temperature events in Greater Manchester are not only directly heatrelated but also due to drownings from swimming in open waters and waterways as well as respiratory problems due to elevated air pollution concentrations and extremely high pollen counts (ibid.). Other impacts include from infrastructure damage and delay (road and rail), water restrictions and fires, both within the city and in the upland hinterlands (see Box 2.1).

\section{Box 2.1 Heat-Related Events and Their Impacts: Evidence from Summer 2018 in the Case Study Area}

Late June/early July 2018 saw a particularly long warm, dry period in Greater Manchester. Between 22 June and 6 July 2018 there were more than five consecutive dry days with ten of those dry days seeing peak temperatures $>25{ }^{\circ} \mathrm{C}$. This is compared with a longer-term June/July average of $64.5 / 67.3 \mathrm{~mm}$ rainfall, $9.7 / 11.7$ rain days ( $>1 \mathrm{~mm}$ rain) and peak temperatures of $18.4 / 20.2^{\circ} \mathrm{C}$ (1982-2010 averages) (Met Office 2018). At the time of writing the event was ongoing, with a Level 3 Heatwave action issued and with the national meteorological office reporting a probable lack of rainfall lasting a month (Manchester Evening News 2018). Peak temperatures exceeded $30{ }^{\circ} \mathrm{C}$ (Fig. 2.6 (top)) and were certainly considerably higher in the city centre where there is no official meteorological station.

The warm, dry conditions contributed to the development of a moorland fire on Saddleworth moor (near Oldham, Greater Manchester), which was so extreme that the army was called to assist fire fighters, schools were closed and local residents evacuated (BBC 2018). The resultant smoke was extensive and severe enough to trigger smoke alarms in buildings in Manchester city centre more than $15 \mathrm{~km}$ away (University of Manchester, pers. com.). At least two other large moorland fires on Bolton's Winter Hill to the north of the city also affected an area greater than $10 \mathrm{~km}^{2}$ (BBC 2018). At least one industrial fire occurred in Rochdale to the north east of the conurbation. The combined effects of the fires, high temperatures and wind flows led to elevated air pollutant concentrations in terms of ozone, fine particulate matter and nitrogen dioxide (Fig. 2.6 (bottom)).

All of these pollutants are regulated for public health. Although no evidence of health effects has yet emerged, it is highly likely that they occurred. Fig. 2.7 provides a rich picture of the expected links between ecosystems, human health and key climate-related indicators. 

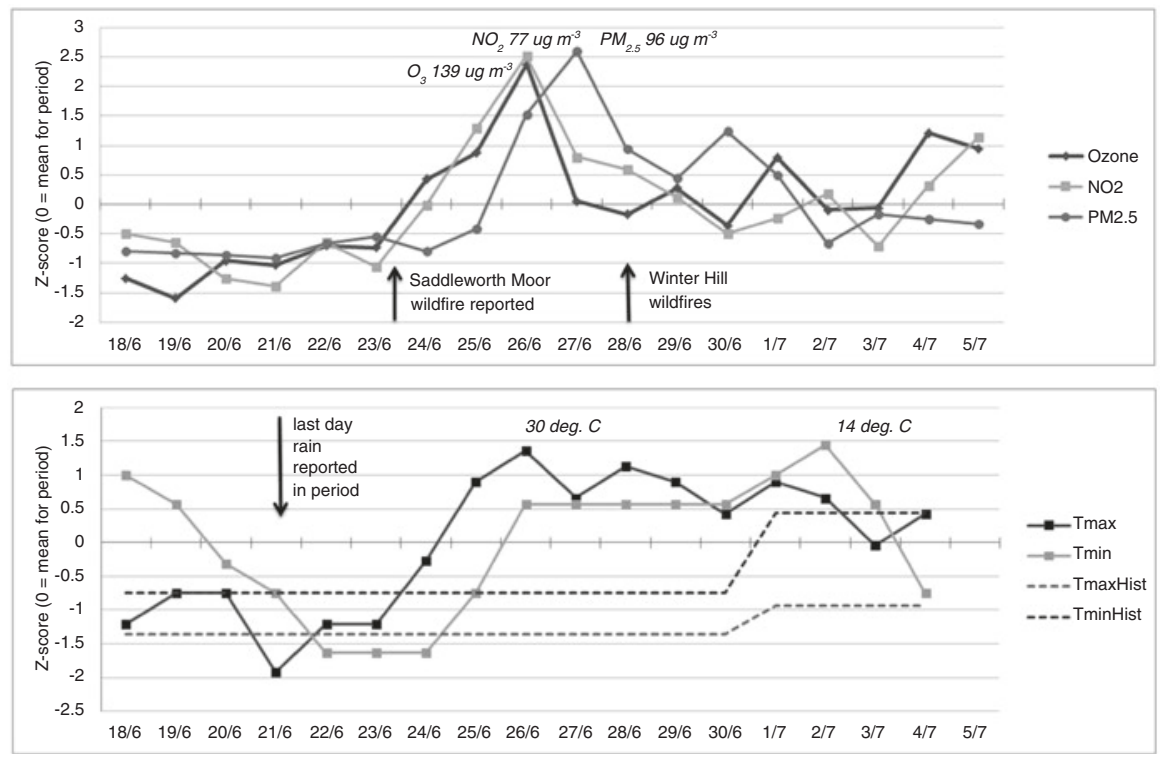

Fig. 2.6 Peak daily concentrations of air pollutants monitored for human health (top) and maxima and minima air temperatures (bottom). The $\mathrm{x}$-axis represents the mean for the period with the $y$-axis showing the extent of deviation around that mean (as standard deviations). Actual values are shown for the peak days/hours (developed from data sourced from: Defra, Rainchester.com, Accuweather, Met Office, Manchester Evening News and the BBC)

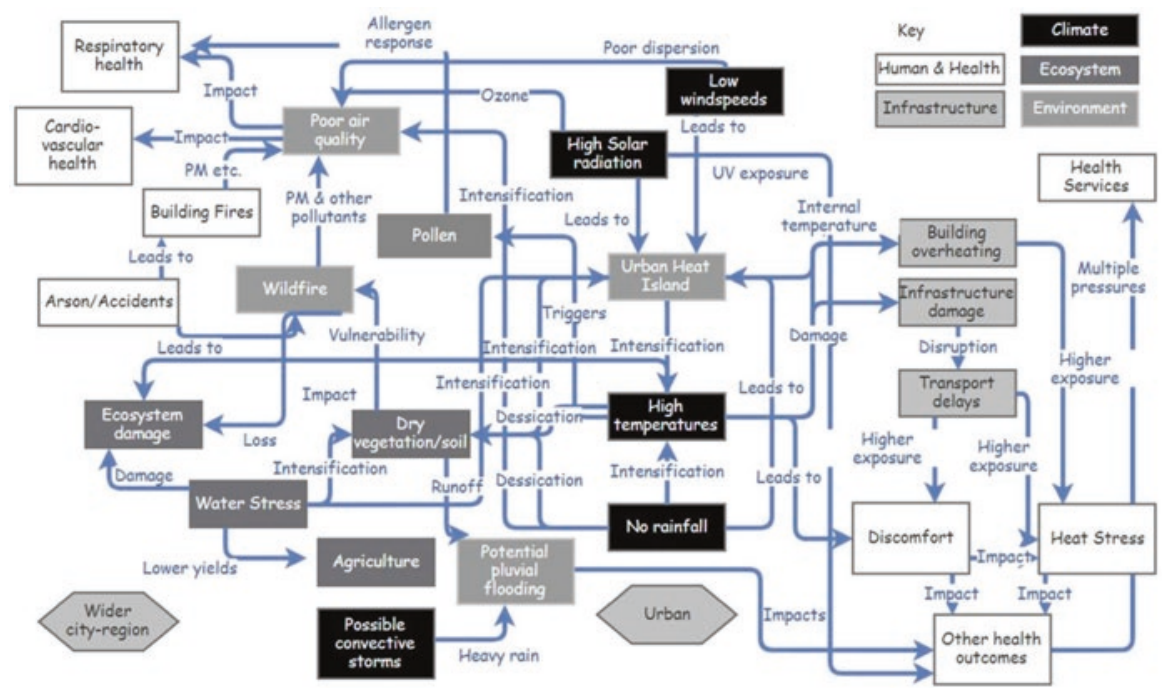

Fig. 2.7 Complex interactions of high temperature events with environmental stressors and health effects. Synthesis of evidence from Box 2.1 and Sect. 2.5 
The trend towards an increasing frequency and severity of heat-related events is significant not only due to impacts on human health, but also due to the implications for energy demand for space cooling as people start to autonomously adapt. Even in relatively cool Manchester, modelling studies suggest that the summer UHI increases air conditioning loads by $~ 7-8 \%$ (Skelhorn et al. 2017). The UHI effect is then an additional factor to consider on top of the estimated mean of 13 cooling degree days per year (days where the mean temperature exceeds $22{ }^{\circ} \mathrm{C}$ ) under the high emissions scenario central estimate for the 2050s (Cavan 2010). More chiller energy is likely to be required to maintain comfortable temperatures, particularly for people who have higher sensitivities to ill-effects, e.g. due to age or pre-existing health conditions (Lindley et al. 2011). It is also highly likely that autonomous adaptation will lead to increases in air conditioning, but only for those who can afford it.

One of the drivers of increasing UHI is urban densification and associated losses of green cover. For example, green cover around Manchester's urban weather station has reduced by $\sim 11 \%$ (2000-2009). Impacts are corroborated by modelling, showing that replacing all vegetation with asphalt would lead to air temperature increases of up to $3.2{ }^{\circ} \mathrm{C}$ in parts of the city (Skelhorn et al. 2014). Presence and abundance of biomass are two of the biodiversity metrics that are positively connected with moderation of extreme events and local climate/air quality regulation (Fig. 2.4) along with taxonomic diversity, species composition, functional diversity and functional identity.

In addition to green space losses a range of other ecosystem and biodiversity metrics are influential in affecting spatial and temporal patterns in the urban microclimate, such as species type and functional traits. There is also the issue of green space degradation and/or modification due to urban factors, including through impacts on biodiversity. Urban ecosystems have distinct abiotic characteristics: higher temperatures, modified/drier soils, higher surface sealing, higher light levels due to artificial lighting and more fragmentation (Schwarz et al. 2017). Urban ecosystems also differ in their composition, functional traits and structures as a result of abiotic factors and management practices (Ziter 2016; Schwarz et al. 2017). The effect can be to modify regulating functions, sometimes reversing beneficial functions for health and well-being. For example, inappropriate management of a large, 30-year-old green roof in Manchester was found to increase both air and surface temperatures. Peak air temperatures above a damaged green roof exceeded those above an adjacent bare roof during some of the hottest periods of an experimental study (Speak et al. 2013a, b). In the damaged roof case, impacts were exacerbated by the removal of vegetation (largely grasses) during an extended drought period. Natural re-colonization to a 'meadow' form took two growing seasons during which time temperature regulating functions continued to be compromised, as well as the other functions that the green roof had been providing, including air pollution removal and regulation of water runoff and water quality (Speak et al. 2012, 2013a, b, 2014).

Clearly, for green spaces to be able to retain their beneficial functions, it will be necessary to adapt associated management practices and consider what sorts of metrics are used to assess change. Fortunately, in terms of temperature, a relatively 
modest 5\% increase in mature tree cover in suburban areas (e.g. Acer campestre (Field Maple), Acer platanoides Globosum (Norway Maple), Acer pseudoplatanus (Sycamore) and Quercus robur (English Oak)) can reduce surface temperatures by $\sim 1{ }^{\circ} \mathrm{C}$. In turn, there are positive impacts for climate mitigation through reductions in energy demand (Skelhorn et al. 2016, 2017). Evidence from studies like these can help fill the void between knowledge and practice by beginning to link specific plant assemblages and species to benefits (Cameron and Blanusa 2016). However, potential trade-offs must also be considered. For example, how effective is evapotranspiration from urban trees under drought conditions and what implications are there for water management for other types of green spaces? Cameron and Blanusa (2016) pose the question of what is the right 'plant palette' for multi-functional green infrastructure, such as aesthetically pleasing road-side amenity green space, which can provide noise and air pollution removal, encourage physical activity, offer pedestrian shading and contain food for pollinators while also being able to tolerate the harsh environment of urban areas in terms of water, nutrients and temperatures. Decisions also need to consider whether some species, despite delivering positive functions, may have drawbacks, e.g. in terms of becoming invasive, generating large amounts of pollen or perhaps being associated with 'nuisance' issues that impact public acceptability, such as damage to pavements with secondary consequences for accessibility, or honeydew release, which itself is an indicator of ecosystem health due to the increased likelihood of tree disease.

There is also the issue that wider urban planning systems are not yet set up to recognise and protect functional traits that link types of green infrastructure to human health benefits (see Heiland et al. Chap. 19, this volume). In the UK, the most common method for evaluating tree loss caused by development is to calculate the change in the number of trees for individual planning applications. However, the number of trees lost or gained in a development reveals little about the associated impacts on human health. Indeed, simple loss/gain metrics can be a serious misrepresentation of the more important biodiversity metrics which underpin benefits. For example, an unpublished study of tree removal on the University of Manchester campus demonstrated that when calculated by number, the proportion of trees lost to development was lower than if calculated by loss of total leaf area and much less if calculated by loss of canopy area (Fig. 2.8). Yet canopy extent (surface shading) is important for temperature regulation. There was also a loss of species richness, albeit one that was lower proportionally compared to the loss of tree numbers. According to estimates generated by the i-Tree Eco tool (produced by the US Forestry Service), the proportion of air pollutants (carbon monoxide, nitrogen dioxide, ozone, sulphur dioxide and $\mathrm{PM}_{2.5}$ ) being captured by campus trees had declined by $23.4 \%$. Of the trees that were felled between 2013 and 2017, the top 10\% $(n=28)$ most effective absorbers of air pollution captured $26 \%$ of the total air pollution removed by campus trees. The results point to a disproportional loss of beneficial functions for human health even if replacement - usually less mature - trees are planted to compensate for losses. 


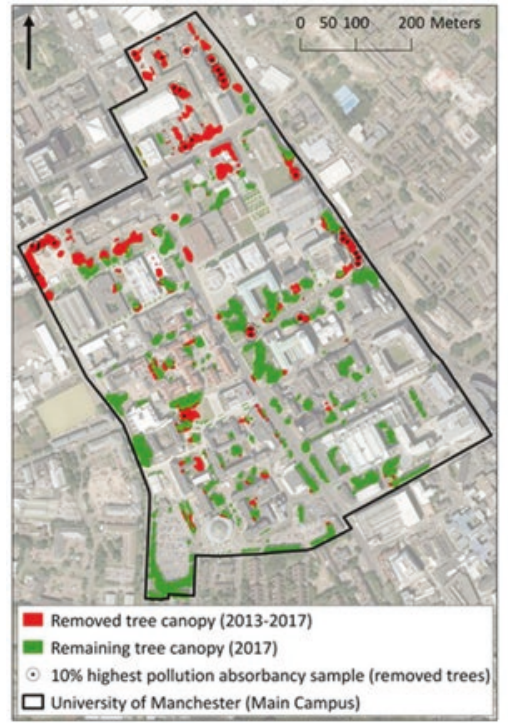

\begin{tabular}{|c|c|c|c|c|}
\hline Indicator & 2013 & 2017 & Change (n) & Change $(\%)$ \\
\hline Number of Trees & 1149 & 874 & -275 & -23.9 \\
\hline Canopy Area (ha) & 5.4 & 3.7 & -1.7 & -32 \\
\hline Leaf Area (ha) & 21.3 & 16.1 & -5.2 & -24.4 \\
\hline Species Richness & 112 & 92 & -20 & -17.9 \\
\hline
\end{tabular}

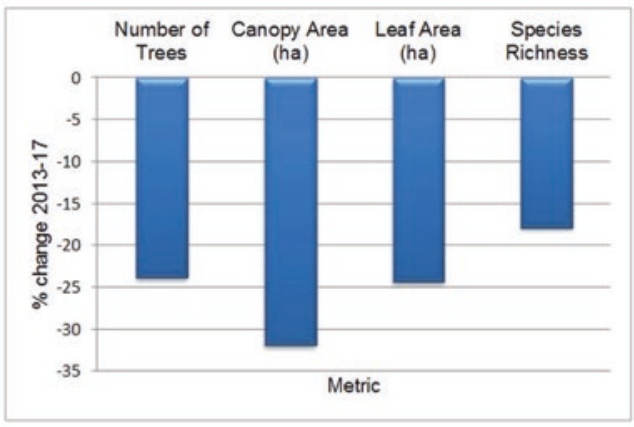

Fig. 2.8 Comparison of metrics associated with tree felling from 2013 to 2017 in an urban district of Manchester (@ Getmapping Plc)

\subsection{Conclusion}

In this chapter, we have presented a summary and synthesis of the current evidence for the links between nature, biodiversity, physical health and climate change with a particular focus on urban areas. We have mainly drawn on recent review papers from the peer reviewed academic literature, supplemented by additional materials from a range of disciplinary fields. Much of the literature is still discipline-based, but increasingly informed by multi-disciplinary research projects and related endeavours. We feel that this is a necessary and positive development, and the greater availability of papers with large and diverse authorships is a positive sign that research is increasingly attempting to draw disciplines together to provide insights into the bigger and most critically important questions for human health and well-being. Nevertheless, we have found little evidence from investigations that explicitly sought to connect climate change with biodiversity and human physical health.

The evidence that does exist suggests that links between biodiversity, physical health and climate change are multiple, interconnected, multi-scale and interdependent. Their interdependence puts into sharp focus the importance of a holistic approach to the major global challenges of health, biodiversity and climate change. Indeed, a holistic approach in policy and practice is as important as it is in scientific research (see Korn et al. Chap. 14; Keune et al. Chap. 15, both this volume). Some of the existing, and newly emerging, challenges for health can be tackled through technological development and research into new interventions, such as new medicines and treatments. However, the extent to which the trends in losses of biodiver- 
sity will curtail the potential for future responses is unclear. Protecting ecosystems and associated biodiversity through a 'maintenance of options' insurance function is important for this reason alone (Díaz et al. 2018). It is also important for helping to address inequalities and for promoting social and environmental justice (Kabisch Chap. 5, this volume), given that in developing countries there is an even stronger reliance on ecosystems for health and well-being than in the developed world (Roy et al. 2018). Ironically, despite developing countries containing most of the world's untapped genetic diversity, developing countries are also where pressures such as urbanisation, demographics and population need, are greatest.

Uncertainties remain about some of the evidence for the links between biodiversity, human physical health and climate change. However, we know enough about the human health-biodiversity-climate change relationship to argue strongly to protect biodiversity and mitigate against climate change. Conceptual and theoretical work, empirical evidence and process modelling are all contributing to an improving evidence base, with increasing emphasis on integrative methods (Calvin and Bond-Lamberty 2018). Nevertheless, the complexities of environmental, social and governance factors mean that there is some way to go for a more complete understanding. Underpinning evidence will need to consider a range of settings and scales, including spatio-temporal dynamics in different climate zones and biomes as well as in the distinct urban habitat that now defines the majority of people's lives. We will also need to further develop our understanding of links between mental and physical health, connections between different body organ systems and the environmental determinants of health/ill-health from the perspective of biodiversity and the natural environment (see de Vries and Snep Chap. 8; Marselle et al. Chap. 9; Cook et al. Chap. 11, all this volume). Studies of the life course also have something to offer here, including environment-focused population cohort studies (see Dadvand et al. Chap. 6, this volume).

Our review reveals that there is still a need for extensive further research into relationships between biodiversity, climate change and human physical health. We still know little about trade-offs and the balance between benefits and harms. Such research is multi-layered and inherently multi-disciplinary. Complexities are compounded due to differing perspectives on issues, for example with some researchers using health as a primary starting point and other researchers starting from the perspective of environmental or ecological processes. The different perspectives are important for developing fuller understandings, but still make the challenges of integrated research all the more demanding, especially at the science-practice interface.

Ultimately, the most pressing questions also include some recognition of the need for action in the light of climate change projections, biodiversity losses and public health demands (De Young Chap. 13, this volume). It will be important to understand and resolve the web of connecting pathways between biological and functional diversity, and human health and well-being (Box 2.1) to identify the main protective roles and ensure that they are retained and enhanced in a range of ecosystems. Given urban growth and economic imperatives, it will be necessary to explore what sort of configurations can be promoted for multiple beneficial ecosystem functioning in different geographical, temporal and social settings. It will also be important to understand how climate change and related stresses will modify functions 
and functional groups, including the development of measurable and robust indicators that can be monitored over time. Other questions then emerge, how can wider landscapes be productive, diverse and climate resilient? How far are climate and other stressors likely to modify the beneficial functioning of the human biome in terms of physical health outcomes? What habitat types and elements of biodiversity in green and blue spaces in urban areas help promote physical health through the normal functioning of the human biome at different stages of the life course? How can these types and elements be considered within the planning process and within health and social care systems? Making progress on these questions is not easy. However, given the finite nature of the planetary boundary and the mounting pressures from a wide range of human drivers they remain some of the most important and urgent for researchers and practitioners alike.

\section{References}

Arbuthnott KG, Hajat S (2017) The health effects of hotter summers and heat-waves in the population of the United Kingdom: a review of the evidence. Environ Health 16(Suppl 1):119

Barton H, Grant M (2006) A health map for the local human habitat. J R Soc Promot Health 126(6):252-253

BBC (2018) England Moor fires. https://www.bbc.co.uk/news/topics/cq5p6wx822pt/englandmoor-fires. Accessed 6 July 2018

Benedict M A, McMahon E T (2002) Green infrastructure: smart conservation for the 21st century. [Online] Available at: wwwsactreeorg/assets/files/greenprint/toolkit/b/greenInfrastructurepdf. Accessed 16 June 2014

Bonebrake TC, Brown CJ, Bell JD, Blanchard JL, Chauvenet A, Champion C, Chen IC, Clark TD, Colwell RK, Danielsen F (2018) Managing consequences of climate-driven species redistribution requires integration of ecology, conservation and social science. Biol Rev 93:284-305

Bowler DE, Buyung-Ali L, Knight TM, Pullin AS (2010) Urban greening to cool towns and cities: a systematic review of the empirical evidence. Landsc Urban Plan 97(3):147-155

Burkart K, Breitner S, Schneider A, Khan MMH, Krämer A, Endlicher W (2014) An analysis of heat effects in different subpopulations of Bangladesh. Int J Biometeorol 58(2):227-237

Buxton RT, McKenna MF, Mennitt D, Fristrup K, Crooks K, Angeloni L, Wittemyer G (2017) Noise pollution is pervasive in U.S. protected areas. Science 356(6337):531-533. https://doi. org/10.1126/science.aah4783c

Caini S, Schellevis F, El-Guerche Séblain C, Paget J (2018) Important changes in the timing of influenza epidemics in the WHO European region over the past 20 years: virological surveillance 1996 to 2016. Eur Secur 23(1):17-00302

Calvin K, Bond-Lamberty B (2018) Integrated human-earth system modeling-state of the science and future directions. Environ Res Lett 13(6):063006

Cameron RW, Blanusa T (2016) Green infrastructure and ecosystem services - is the devil in the detail? Ann Bot 118:377-339

Carding S, Verbeke K, Vipond DT, Corfe BM, Owen LJ (2015) Dysbiosis of the gut microbiota in disease. Microb Ecol Health Dis 26(26191). https://doi.org/10.3402/mehd.v26.26191

Carporn SJM, Emmett BA (2009) Threats from air pollution and climate change to upland systems: past, present and future. In: Bonn A, Allott T, Hubacek K, Stewart J (eds) Drivers of environmental change in uplands. Routledge, Oxon, pp 34-58

Cavan G (2010) Climate change projections for Greater Manchester. Manchester: EcoCities project, University of Manchester. Available at: http://media.adaptingmanchester.co.uk.ccc.cdn. faelix.net/sites/default/files/Climate_change_projections_GM_final.pdf. Accessed 6 July 2018

Challinor AJ et al (2018) Transmission of climate risks across sectors and borders. Phil Trans R Soc A 376:20170301 
Cheung HKW (2011) An urban heat island study for building and urban design. Manchester: $\mathrm{PhD}$ thesis, University of Manchester

Clark NE, Lovell R, Wheeler BW, Higgins SL, Depledge MH, Norris K (2014) Biodiversity, cultural pathways, and human health: a framework. Trends Ecol Evol 29(4):198-204

Coutts C, Hahn M (2015) Green infrastructure, ecosystem services, and human health. Int J Environ Res Public Health 12:9768-9798

Cox DTC, Gaston KJ (2018) Human-nature interactions and the consequences and drivers of provisioning wildlife. Phil Trans R Soc 373:20170092

Curtis S, Fair A, Wistow J, Val DV \& Oven K (2017) Impact of extreme weather events and climate change for health and social care systems. Environ Health 16(Suppl 1):128

Dahlgren G, Whitehead M (1991) Policies and strategies to promote social equity in health. Institute for Futures Studies, Stockholm

Dahlgren G, Whitehead M (2007) European strategies for tackling social inequities in health: levelling up, part 2. WHO Regional Office for Europe, Copenhagen

Díaz S, Pascual U, Stenseke M, Martín-López B, Watson RT, Molnár Z, Hill R, Chan KMA, Baste IA, Brauman KA, Polasky S, Church A, Lonsdale M, Larigauderie A, Leadley PW, van Oudenhoven APE, van der Plaat F, Schröter M, Lavorel S, Aumeeruddy-Thomas Y, Bukvareva E, Davies K, Demissew S, Erpul G, Failler P, Guerra CA, Hewitt CL, Keune H, Lindley S, Shirayama Y (2018) Assessing nature's contributions to people. Science 359(6373):270-272

Dobson A, Cattadori I, Holt RD, Ostfeld RS, Keesing F, Krichbaum K, Rohr JR, Perkins SE, Hudson PJ (2006) Sacred cows and sympathetic squirrels: the importance of biological diversity to human health. PLoS Med 3(6):714-718

Doherty RM, Heal MR, O'Connor FM (2017) Climate change impacts on human health over Europe through its effect on air quality. Environ Health 16(Suppl 1):1-18

European Environment Agency (2017) Climate change, impacts and vulnerability in Europe: an indicator based report. European Environment Agency, Copenhagen

European Environment Agency (2018) About urban environment. [Online] Available at: https:// www.eea.europa.eu/themes/sustainability-transitions/urban-environment/about-urban-environment. Accessed 10 Jan 2018

Fann N, Alman B, Broome RA, Morgan GG, Johnston FH, Pouliot G, Rappold AG (2018) The health impacts and economic value of wildland fire episodes in the US: 2008-2012. Sci Total Environ 610-611:802-809

Fernandez LS, Byard D, Lin C-C, Benson S (2002) Frail elderly as disaster victims: emergency management strategies. Prehosp Disaster Med 17(2):67-74

Fisher JE, Andersen ZJ, Loft S, Pedersen M (2017) Opportunities and challenges within urban health and sustainable development. Curr Opin Environ Sustain 25:77-83

Flandroy L, Poutahidis T, Berg G, Clarke G, Dao M-C, Decaestecker E, Furman E, Haahtela T, Massart S, Plovier H (2018) The impact of human activities and lifestyles on the interlinked microbiota and health of humans and of ecosystems. Sci Total Environ 627:1018-1038

Garrett WS (2015) From cell biology to the microbiome: an intentional infinite loop. J Cell Biol 210(1):7-8

Grellier J, White MP, Albin M, Bell S, Elliott LR, Gascón M, Gualdi S, Mancini L, Nieuwenhuijsen MJ, Sarigiannis DA (2017) BlueHealth: a study programme protocol for mapping and quantifying the potential benefits to public health and well-being from Europe's blue spaces. BMJ Open 7:e016188

Grize L, Huss A, Thommen O, Schindler C, Braun-Fahrländer C (2005) Heatwave 2003 and mortality in Switzerland. Swiss Med Wkly 135:200-205

Hajat S (2017) Health effects of milder winters: a review of evidence from the United Kingdom. Environ Health 16(Suppl 1):109

Hallmann CA, Sorg M, Jongejans E, Siepel H, Hofland N, Schwan H, Stenmans W, Müller A, Sumser H, Hörren T (2017) More than 75 percent decline over 27 years in total flying insect biomass in protected areas. PLoS One 12(10):1-21

Haluza D, Schönbauer R, Cervinka R (2014) Green perspectives for public health: a narrative review on the physiological effects of experiencing outdoor nature. Int J Environ Res Public Health 11:5445-5461 
Harrison PA, Berry PM, Simpson G, Haslett JR, Blicharska M, Bucur M, Dunford R, Egoh B, Garcia-Llorente M, Geamănă N, Geertsema W, Lommelen E, Meiresonne L, Turkelboom F (2014) Linkages between biodiversity attributes and ecosystem services: a systematic review. Ecosyst Serv 9:191-203

Hartig T, Mitchell R, de Vries S, Frumkin H (2014) Nature and health. Annu Rev Public Health 35:207-228

IPBES (2016) Pollinators, pollination and food production. Secretariat of the Intergovernmental Science-Policy Platform on Biodiversity and Ecosystem Services, Bonn

Jenkins G, Murphy J, Sexton S, Lowe J, Jones P, Kilsby C (2009) UK climate projections: briefing report. Met Office Hadley Centre, Exeter

Johnson H, Kovats S, McGregor G, Stedman J, Gibbs M, Walton H, Cook L (2004) The impact of the 2003 heat-wave on mortality and hospital admissions in England. Epidemiology 15(4):6-11

Kaczynski A, Henderson K (2007) Environmental correlates of physical activity: a review of evidence about parks and recreation. Leis Sci 29:315-354

Karkman A, Lehtimäki J, Ruokolainen L (2017) The ecology of human microbiota: dynamics and diversity in health and disease. Ann N Y Acad Sci 1399(1):78-92

Kellogg J, Wang J, Flint C, Ribnicky D, Kuhn P, De Mejia EGl, Raskin I, Lila MA (2010) Alaskan wild berry resources and human health under the cloud of climate change. J Agric Food Chem 58(7):3884-3900

Keniger LE, Gaston KJ, Irvine KN, Fuller RA (2013) What are the benefits of interacting with nature? Int J Environ Res Public Health 10:913-935

Klinger C, Landeg O, Murray V (2014) Power outages, extreme events and health: a systematic review of the literature from 2011-2012. PLOS Curr Disasters, Issue Edition 1

Lake IR (2017) Food-borne disease and climate change in the United Kingdom. Environ Health 16:117

Landrigan PJ, Fuller R, Acosta NJ, Adeyi O, Arnold R, Baldé AB, Bertollini R, Bose-O'Reilly S, Boufford JI, Breysse PN (2018) The lancet commission on pollution and health. Lancet 391:462-512

Latif MT, Othman M, Idris N, Juneng L, Abdullah AM, Hamzah WP, Khan MF, Sulaiman NMN, Jewaratnam J, Aghamohammadi N (2018) Impact of regional haze towards air quality in Malaysia: a review. Atmos Environ 177:28-44

Levermore G, Parkinson J, Lee K, Lindley S (2017) The increasing trend of the urban heat island intensity. Urban Climate 24:360-368

Liddicoat C, Bi P, Waycott M, Glover J, Lowe AJ, Weinstein P (2018) Landscape biodiversity correlates with respiratory health in Australia. J Environ Manag 206:113-122

Lindberg F (2007) Modelling the urban climate using a local governmental geo-database. Meteorol Appl 14:263-273

Lindley SJ, Handley JF, Theuray N, Peet E, McEvoy D (2006) Adaptation strategies for climate change in the adaptation strategies for climate change in the related risk in UK urban areas. J Risk Res 9(5):543-568

Lindley S, O’Neill J, Kandeh J, Lawson N, Christian R, O’Neill M (2011) Climate change, justice and vulnerability. Joseph Rowntree Foundation, York

Linton M-J, Dieppe P, Medina-Lara A (2016) Review of 99 self-report measures for assessing well-being in adults: exploring dimensions of well-being and developments over time. BMJ Open 6:e10641

Lovell R, Wheeler BW, Higgins SL, Irvine KN, Depledge MH (2014) A systematic review of the health and Well-being. J Toxicol Environ Health B 17:1-20

Lowe D, Ebi KL, Forsberg B (2013) Factors increasing vulnerability to health effects before, during and after floods. Int J Environ Res Public Health 10(12):7015-7067

LWEC (2015) Living with environmental change: health report card. [Online] Available at: http:// www.nerc.ac.uk/research/partnerships/ride/lwec/report-cards/health/. Accessed 23 Feb 2018

Mace GM, Norris K, Fitter AH (2012) Biodiversity and ecosystem services: a multilayered relationship. Trends Ecol Evol 27(1):19-26

Manchester Evening News (2018) Firefighters continue to tackle Winter Hill blaze which has caused 'pure devastation' - live updates. https://www.manchestereveningnews.co.uk/news/ greater-manchester-news/winter-hill-fire-updates-manchester-14842549. Accessed 6 July 2018 
Markevych I, Schoierer J, Hartig T, Chudnovsky A, Hystad P, Dzhambov AM, de Vries S, TrigueroMas M, Brauer M, Nieuwenhuijsen MJ, Lupp G, Richardson EA, Astell-Burt T, Dimitrova D, Feng X, Sadeh M, Standl M, Heinrich J, Fuertes E (2017) Exploring pathways linking greenspace to health: theoretical and methodological guidance. Environ Res 158:301-317

McMichael AJ (2013) Globalization, climate change, and human health. N Engl J Med 368:1335-1343

Met Office (2018) Woodford climate 1981-2010. https://www.metoffice.gov.uk/public/weather/ climate/gcqrqyr80. Accessed 6 July 2018

Mölter A, Lindley S (2015) Influence of walking route choice on primary school children's exposure to air pollution-a proof of concept study using simulation. Sci Total Environ 530:257-262

Moreno DA, Carvajal M, López-Berenguer C, García-Viguera C (2006) Chemical and biological characterisation of nutraceutical compounds of broccoli. J Pharm Biomed Anal 41(5):1508-1522

Nile SH, Park SW (2014) Edible berries: bioactive components and their effect on human health. Nutrition 30:134-144

Norton BA, Coutts AM, Livesley SJ, Harris RJ, Hunter AM, Williams NSG (2015) Planning for cooler cities: a framework to prioritise green infrastructure to mitigate high temperatures in urban landscapes. Landsc Urban Plan 134:127-138

Odamaki T, Kato K, Sugahara H, Hashikura N, Takahashi S, Xiao J-z, Abe F, Osawa R (2016) Age-related changes in gut microbiota composition from newborn to centenarian: a crosssectional study. BMC Microbiol 16(90):12

Oke T (1982) The energetic basis of the urban heat island. Q J R Meteorol Soc 108(445):1-24

Paredes-Lopez O, Cervantes-Ceja ML, Vigna-Pérez M, Hernández-Pérez T (2010) Berries: improving human health and healthy aging, and promoting quality life-a review. Plant Foods Hum Nutr 65(3):299-308

Poumadere M, Mays C, Le Mer S, Blong R (2005) The 2003 heat wave in France: dangerous climate change here and now. Risk Anal 25(6):1483-1494

Rader R, Bartomeus I, Garibaldi LA, Garratt MP, Howlett BG, Winfree R, Cunningham SA, Mayfield MM, Arthur AD, Andersson GK (2016) Non-bee insects are important contributors to global crop pollination. PNAS 113 (1):146-151

Recio A, Linares C, Ramón Banegas J, Díaz J (2016) Road traffic noise effects on cardiovascular, respiratory, and metabolic health: an integrative model of biological mechanisms. Environ Res 146:359-370

Renz H, Holt PG, Inouye M, Logan AC, Prescott SL, Sly PD (2017) An exposome perspective: earlylife events and immune development in a changing world. J Allergy Clin Immunol 140(1):24-40

Robinson C, Bouzarovski S, Lindley S (2018) Underrepresenting neighbourhood vulnerabilities? The measurement of fuel poverty in England. Energy Res Soc Sci 36:79-93

Rogalski MA, Gowler CD, Shaw CL, Hufbauer RA, Duffy MA (2017) Human drivers of ecological and evolutionary dynamics in emerging and disappearing infectious disease systems. Philos Trans B 372 (1712):20160043

Rook G (2013) Regulation of the immune system by biodiversity from the natural environment: an ecosystem service essential to health. Proc Natl Acad Sci 110(46):18360-18367

Roy M, Shemdoe R, Hulme D, Mwageni N, Gough A (2018) Climate change and declining levels of green structures: life in informal settlements of Dar es Salaam, Tanzania. Landsc Urban Plan 180:282-293

Ruokolainen L, Lehtimäki J, Karkman A, Haahtela T, von Hertzen L, Fyhrquist N (2017) Holistic view on health: two protective layers of biodiversity. Ann Zool Fenn 54:39-49

Sandifer PA, Sutton-Grier AE, Ward BP (2015) Exploring connections among nature, biodiversity, ecosystem services and human health and well-being: opportunities to enhance health and biodiversity conservation. Ecosyst Serv 12:1-15

Schmeller DS, Weatherdon LV, Loyau A, Bondeau A, Brotons L, Brummitt N, Geijzendorffer IR, Haase P, Kuemmerlen M, Martin CS (2018) A suite of essential biodiversity variables for detecting critical biodiversity change. Biol Rev 93(1):L55-L71

Schwarz N, Moretti M, Bugalho MN, Davies ZG, Haase D, Hack J, Hof A, Melero Y, Pett TJ, Knapp S (2017) Understanding biodiversity-ecosystem service relationships in urban areas: a comprehensive literature review. Ecosyst Serv 27:161-171 
Schweitzer MD, Calzadilla AS, Salamo O, Sharifi A, Kumar N, Holt G, Campos M, Mirsaeidi M (2018) Lung health in era of climate change and dust storms. Environ Res 163:36-42. https:// doi.org/10.1016/j.envres.2018.02.001

Seksik P, Landman C (2015) Understanding microbiome data: a primer for clinicians. Dig Dis 33(suppl 1):11-16. https://doi.org/10.1159/000437034

Skelhorn CP, Lindley SJ, Levermore G (2014) The impact of vegetation types on air and surface temperatures in a temperate city: a fine scale assessment in Manchester, UK. Landsc Urban Plan 121:129-140

Skelhorn CP, Levermore G, Lindley SJ (2016) Impacts on cooling energy consumption due to the UHI and vegetation changes in Manchester, UK. Energ Build 122:150-159

Skelhorn CP, Lindley SJ, Levermore G (2017) Urban greening and the UHI: seasonal trade-offs in heating and cooling energy consumption in Manchester, UK. Urban Clim 23:173-187

Smith C, Lawson N (2012) Exceeding climate thresholds: extreme weather impacts on the environment and population of greater Manchester. North West Geography, Issue 1

Smith C, Lindley S, Levermore G (2009) Estimating spatial and temporal patterns of urban anthropogenic heat fluxes for UK cities: the case of Manchester. Theor Appl Climatol 98:19-35

Speak AF, Rothwell JJ, Lindley SJ, Smith CL (2012) Urban particulate pollution reduction by four species of green roof vegetation in a UK city. Atmos Environ 61:283-293

Speak AF, Rothwell JJ, Lindley SJ, Smith CL (2013a) Rainwater runoff retention on an aged intensive green roof. Sci Total Environ 461:28-38

Speak A, Rothwell JJ, Lindley S, Smith C (2013b) Reduction of the urban cooling effects of an intensive green roof due to vegetation damage. Urban Clim 3:40-55

Speak AF, Rothwell JJ, Lindley SJ, Smith CL (2014) Metal and nutrient dynamics on an aged intensive green roof. Environ Pollut 184:33-43

Sproken-Smith RA, Oke TR (1999) Scale modelling of nocturnal cooling of urban parks. BoundLayer Meteorol 93:287-312

Stollberger C, Lutz W, Finsterer J (2009) Heat-related side-effects of neurological and nonneurological medication may increase heat wave fatalities. Eur J Neurol 16(7):879-882

Teixeira A, Eiras-Dias J, Castellarin SD, Gerós H (2013) Berry Phenolics of grapevine under challenging environments. Int J Mol Sci 14(9):18711-18739

van den Bosch M, Sang AO (2017) Urban natural environments as nature-based solutions for improved public health - a systematic review of reviews. Environ Res 158:373-384

White MP, Wheeler BW, Herbert S, Alcock I, Depledge MH (2014) Coastal proximity and physical activity: is the coast an under-appreciated public health resource? Prev Med 69:135-140

Wilby RL (2003) Past and projected trends in London's urban heat island. Weather 58(7):251-259

Ziter C (2016) The biodiversity-ecosystem service relationship in urban areas: a quantitative review. Oikos 125:761-768

Open Access This chapter is licensed under the terms of the Creative Commons Attribution 4.0 International License (http://creativecommons.org/licenses/by/4.0/), which permits use, sharing, adaptation, distribution and reproduction in any medium or format, as long as you give appropriate credit to the original author(s) and the source, provide a link to the Creative Commons license and indicate if changes were made.

The images or other third party material in this chapter are included in the chapter's Creative Commons license, unless indicated otherwise in a credit line to the material. If material is not included in the chapter's Creative Commons license and your intended use is not permitted by statutory regulation or exceeds the permitted use, you will need to obtain permission directly from the copyright holder.

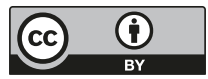

